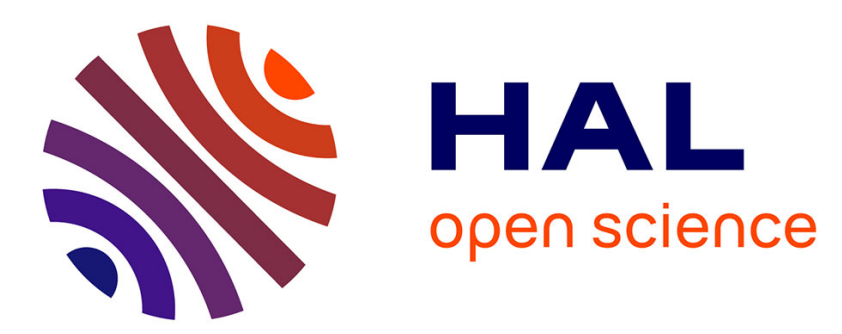

\title{
Euphemism as a core feature of patientese: A comparative study between English and French
}

Pascaline Faure

\section{To cite this version:}

Pascaline Faure. Euphemism as a core feature of patientese: A comparative study between English and French. Language Learning in Higher Education, 2016, 6 (1), 10.1515/cercles-2016-0008 . hal03510715

\section{HAL Id: hal-03510715 \\ https://hal.science/hal-03510715}

Submitted on 4 Jan 2022

HAL is a multi-disciplinary open access archive for the deposit and dissemination of scientific research documents, whether they are published or not. The documents may come from teaching and research institutions in France or abroad, or from public or private research centers.
L'archive ouverte pluridisciplinaire HAL, est destinée au dépôt et à la diffusion de documents scientifiques de niveau recherche, publiés ou non, émanant des établissements d'enseignement et de recherche français ou étrangers, des laboratoires publics ou privés. 
Pascaline Faure

\title{
Euphemism as a core feature of patientese: A comparative study between English and French
}

\begin{abstract}
The purpose of this lexicological study is to present a typology of patients' euphemizing lay denominations of medical terms illustrated by examples in English and French. Various textbooks and lexicons dealing with English and French for medical purposes served as corpora. The euphemisms were classified according to the three semantic processes by means of which they were created: widening (Eng. down below for "genitals" and Fr. poitrine [lit. 'chest'] for "breast"), reduction (Eng. miss* for "miscarriage" and Fr. MST [lit. 'STD'] for "sexuallytransmitted disease"), and analogy (Eng. engine for "heart" and Fr. tuyauterie [lit. 'pipes'] for "urinary system"). Underlying these semantic processes, the same structural metaphors in both languages were identified: VAGUER IS BETTER (widening), LESS OF FORM IS LESS OF CONTENT (reduction), and THE BODY IS A MACHINE/ORGANS ARE CONTAINERS (analogy). The examples show that these categories are not fully exclusive. Because lay terms used by patients during interview are a source of major misunderstandings on the part of healthcare professionals who are not native speakers of their patients' language, pedagogical guidelines are provided so as to encourage Language for Medical Purposes (LMP) teachers to incorporate the study of patientese into their course. In my conclusion, I offer two hypotheses that both need further exploration: the probable evolution of patients' terminology towards enhanced technicality under the influence of both medical TV series and the Internet, and consequently, the plausible use of technical terms as new euphemisms.
\end{abstract}

Keywords: Languages for Medical Purposes (LMP), doctor/patient communication, lay terminology, technical/medical terminology, euphemism

Pascaline Faure, Sorbonne Universités, UPMC Université Paris 06

Pierre and Marie Curie School of Medicine, 91 Boulevard de l'Hôpital 75013 Paris, France, E-mail: pascalinefaure@ orange.fr 
Early on, I was working in a headinjury unit when an elderly lady told me she wanted to "spend a penny". I thought that she wanted to go down to the kiosk to buy a snack. ${ }^{1}$

Patientese is a complex and rich language teeming with various figures of speech, archaisms (Faure 2015), slang words and sometimes even an unconventional use of grammar (e.g. the measles, the brains [Dirckx 1983: 132]). As this has never been done before, I thought a comparative analysis of English and French lay terms would make LMP teachers aware of this language issue and encourage them to help non-native English- or French-speaking healthcare professionals improve their understanding of their patients. Due to limitations of space, I decided to restrain the scope of the present paper to the study of euphemism.

\section{Introduction}

Extensive research has been devoted to patients' health literacy and how the language used by physicians during medical consultations can have an impact on perception of disease and compliance with treatment (Tailor and Ogden 2009; Tanguy et al. 2011). For example, while patients would rather receive their diagnoses in technical than in lay terms (Ogden and Branson 2003), they are likely to be more satisfied with encounters in which a physician adjusts his language to match theirs and does not use technical jargon (Williams and Ogden 2004). These studies consistently confirm that patients have difficulty comprehending medical jargon and that the vocabulary gap is a substantial barrier to health information access for laypersons (ZengTreitler and Tse 2006).

Yet, to my knowledge, hardly any research has focused on exploring physicians' understanding of the lay terms used by their patients, especially when they are not native speakers of their patients' language. A seemingly obvious reason would be that "doctors are bilingual: they speak their native everyday language, but they are also fluent in medical language" (Ong et al. 1995: 910). However, even in the case of healthcare professionals who are

\footnotetext{
${ }^{1}$ From the article "The doctor and nurses putting lives at risk because they can't speak English" by John Naish, published in the Daily Mail, 30 March 2012.
} 
native speakers of their patients' language, Roger Shuy (1983: 190) warns: "The patient may also have a medical, social, or regional vocabulary that is at odds with that of the physician."

Over the last 20 years, there has been a huge increase ${ }^{2}$ in the number of foreign healthcare professionals, many of whom practice in a language that they are not native speakers of. And if the technical language, often referred to as medicalese, is translingual, the language used by patients and which I will call patientese - a term I have borrowed from Dirckx (1983) - differs greatly. However, as LMP teachers, we tend to focus on technical language because it is usually the language that we find most difficult and we usually teach for occupational purposes. And when we think "professional", we think "technical". Yet the misunderstandings that non-native English- or French-speaking healthcare professionals may be faced with rarely arise from a lack of knowledge of technical language but rather of the lay language that patients use during interview.

Therefore, in this study I propose to present a typology of patients' euphemizing lay denominations of medical terms illustrated by examples in English and French. In the first part, I define the concept of euphemism and the role it may play in medical communication. In the second part, I present a typology of patients' euphemizing lay denominations of medical terms illustrated by examples in English and in French. The euphemisms are classified according to the semantic processes by means of which they are created. For the purposes of analysis, I used the content of textbooks and lexicons dealing with English and French for medical purposes: Good practice (McCullagh and Wright 2008), Manual of English for the overseas doctor (Parkinson 1999), Professional English in use: Medicine (Glendinning and Howard 2007), English in medicine (Glendinning and Holmström 2004) and Medical IELTS: A workbook for international doctors and Plab candidates (Sales 2004) for the English language, and Les mots de la médecine (Bouché 1994), Le français des médecins (Fassier and Talavera-Goy 2008), Dictionnaire des difficultés du français médical (Quérin 2007) and Santé-médecine.com (Mourlhon-Dallies 2004) for the French language. Because it is now acknowledged that lay terms used by patients during interview can be a source of major misunderstandings, in the third part I propose pedagogical guidelines to encourage LMP teachers to incorporate the study of patientese into their courses.

\footnotetext{
${ }^{2}$ According to the NHS, in 2014, a third of the doctors working in the UK came from another country. According to the American Medical Association, in 2013, foreign doctors represented 27\% of the physicians practicing in the US. In France, the number of foreign doctors increased by 43\% between 2008 and 2013.
} 
The conclusion addresses two issues that both still need further exploration: the probable evolution of patients' terminology towards enhanced technicality under the influence of both medical TV series and the Internet, and consequently, the plausible use of technical terms as new euphemisms.

\section{Euphemism and its impact on patients' health}

Euphemism is usually defined as "the substitution of an agreeable or inoffensive expression for one that may offend or suggest something unpleasant. The origin of this word is Greek euphèmismos, from euphēmos auspicious, sounding good, from eu- + phèmē speech, from phanai to speak." 3

For Ralph Keyes (2010: 6-8), "Euphemisms represent a flight to comfort, a way to reduce tension when conversing. They are comfort words [...] substituted for ones that make us uneasy". "[They] gestate in the loam of our most primitive emotions" (2010: 31). For Joseph Williams ${ }^{4}$ (1975), "Euphemism is such a pervasive human phenomenon, so deeply woven into virtually every known culture, that one is tempted to claim that every human has been pre-programmed to find ways to talk about tabooed subjects."

In the Victorian period, for example, euphemism peaked in the English language as a result of the constrictive moral values of the era (Marsh 1998: 215-30). Marsh understands the Victorian euphemizing tendency as a process of "making language decent" and examines the proliferation of Latinisms (particularly within medicine) and "frenchified prudery" within this period as driven by a euphemistic purgation of the language: "limb" for "leg" and "derriere" for "buttock".

According to Jean Tournier (2004: 155), there are three domains that are considered to be tabooed: beliefs, the human body and its functions, and morality and society. To illustrate the "human body and its functions" category, Tournier mentions "body parts", "bodily effluvia", "nakedness", "sexuality", "mental illness", "old age" and "death". For Keith Allan and Kate Burridge (2006: 101),

[o]ne reason that body parts are so ticklish to talk about has nothing to do with their anatomical delicacy or even their sexual functions and everything to do with the liquids and

\footnotetext{
${ }^{3}$ Source: www.merriam-webster.com.

${ }^{4}$ Cited by Keyes (2010).
} 
gases that emerge from them. In an evolutionary anomaly, body parts such as the behind and the genitalia are used both for sex and secretion. This makes them doubly difficult to discuss. If anything, the elimination of body wastes is even more embarrassing to talk about than sex. As a result, it is one of our leading sources of euphemisms.

In the corpora I used, I noticed that euphemisms were not only motivated by a desire to refer to taboo issues in a more culturally acceptable way but that they were also used as a way to make the concept behind the name less frightening (e.g. barbs for 'barbiturics' and Doc for 'Doctor' in English, and lexo for Lexomil@ and hosto for 'hôpital' in French). This observation leads one to consider the etymological meaning of the word "euphemism" in its broadest sense, that is to say to "speak good" both for the others (co-enunciator[s]) and for oneself (enunciator).

It is important to note that medical terms can also be used euphemistically. For instance, Ralph Keyes (2010) writes that, when asked about how they would refer to their inability to develop or maintain an erection of the penis during sexual intercourse, English male patients find the lay term "impotence" more aggressive than the medical term "erectile dysfunction" and that they favour its abbreviated version ("ED"). This observation shows that we cannot relate euphemisms exclusively to lay terms but rather that the type of euphemism (lay or technical term) will depend on the signified and might vary from one patient to another. Indeed, a term that is difficult or unfamiliar to one person may not be so to another, due to education, personal experience, and other socio-psychological factors (Zeng-Treitler et al. 2008). Usage may also vary from one period of time to another. Thus, a word that might be perceived as a euphemism at a certain time might have been considered offensive in the past or might be considered offensive later on by dint of being used through a process that Steven Pinker (2007) has called the "euphemism treadmill”. For instance, cherry was once considered more respectable than hymen, whereas now the former is thought to be vulgar and the latter chaste.

Studying the use of euphemisms in the language used by patients is of high interest from a medical point of view as the choice of words might have an impact on patients' perception of their disease as well as on their compliance with treatments, as was demonstrated in two studies: "The role of medical language in changing public perceptions of illness" (Young et al. 2008) and "Avoiding the term 'obesity': an experimental study of the impact of doctors' language on patients' beliefs" (Tailor and Ogden 2009). The first study was designed to investigate the impact of medical terminology on the perception of diseases that were newly medicalized (e.g. 
"androgenic alopecia" vs "male pattern baldness") and that of diseases that had been recognized for a long time (e.g. "pharyngitis" vs "sore throat"). The researchers demonstrated that the use of medical language in communication could induce bias in perception and that a change in terminology resulted in a disease being perceived as more serious for newly medicalized conditions: e.g. "gastroesophageal reflux disease" was perceived as more severe than "heartburn". Yet for long-established medical conditions, researchers found that it did not make any difference in perception: e.g. "myocardial infarction" was considered as severe as "heart attack". The second study aimed at exploring the relative impact of using the term "obese" compared to GPs' preferred euphemism on patients' beliefs about the problem. The first stage of the study showed that GPs avoided using the term "obese" and preferred to use a euphemism (e.g. "your weight may be damaging your health"). The second stage showed that the term "obese" made patients believe that the problem had more serious consequences and made them feel more anxious and upset than when the same symptoms were labelled using the euphemism. Based on this "medicalese $=$ seriousness" process, the pharmaceutical industry "sells" new diseases, some of which are only newly medicalized but long-acknowledged ailments: e.g. “disruptive mood dysregulation disorder", which, according to a number of psychiatrists, ${ }^{5}$ simply describes childhood tantrums, a trend named "disease mongering" (Faure 2014).

\section{3 "Euphedicine"6}

Joseph Williams (1975) suggests five general semantic processes by means of which euphemisms are created: borrowing, widening, semantic shift, metaphorical transfer and phonetic distortion. Jean Tournier (2004) names six means of euphemizing significant units: negation, metaphor, metonymy, borrowing, circumlocution and reduction. This analysis has led me to limit these figures to three major processes: widening, reduction and analogy. Behind these semantic processes, I was able to identify the same structural metaphors in both languages: VAGUER IS BETTER (widening), LESS OF FORM IS LESS OF CONTENT (reduction), and THE BODY IS A MACHINE (analogy). These categories are not fully exclusive.

\footnotetext{
${ }^{5}$ http://www.thedailybeast.com/articles/2013/04/11/dsm-v-hoarding-binge-eating-more-new-mental-disorderdiagnoses.html.

${ }^{6}$ A term coined by myself and made of the two words "euphemism" and "medicine".
} 
According to George Lakoff and Mark Johnson (2003: 3-14), "metaphor is pervasive in everyday life" and has "a basis in our physical and cultural experience". The fact that every human being shares the same kind of body and therefore experiences the same physical sensations explains why the same metaphors are to be found in both languages. If all experience is first physical, it is also cultural, and for that reason it does not come as a surprise that the same taboos should be found in both languages. The metaphorising process allows human beings to conceptualize and thus grasp the meaning of otherwise overly abstract notions such as love and evil. But it is also a way for them to act on a certain reality. For instance, in case of embarrassment, one may feel the need to downplay or avoid certain elements for the purpose of eluding a painful reality: e.g. growth for 'cancer'.

\subsection{Widening: VAGUER IS BETTER}

Some lay terms allow one to allude to taboo topics in a very remote way. The lack of preciseness allows the term to remain unobtrusive. For instance, referring to genitals is always quite embarrassing for many patients, and male patients use different widening or vague terms, including thing, private parts, privates (les parties in French), groin, crotch, and loins.

Female English patients may also use expressions such as "down below" or "down there": e.g. when suffering from metrorrhagia, an English patient may say: "I have bleeding from down below"; when suffering from vaginal discharge, she may say: "I'm losing down there". In French, patients may use the expression en bas ('down') for the genital area, devant ('front') for the vaginal area and derrière ('back') for the anal area, a word which also designates the buttock, otherwise called fesses (a word borrowed from the Latin fissa 'anus, buttock', itself from fissum 'slit'). Likewise, in English, the anal/rectum area may be referred to as "back passage" whereas the "front passage" refers to the vagina, and the "buttock" may be referred to as bottom, behind, rear and backside. If a patient suffers from her vagina or her breast(s), she may use respectively the expressions "up inside" and "in my top part" in English. Some English women may prefer chest, bust or bosom to 'breast' like some French women who may choose to talk about their poitrine ('chest') or their buste instead of their seins. English patients may say "I haven't got much" to refer to their small breasts/testicles.

In English, some patients may say: "I haven't been for x days" when constipated, and "I can't manage" when impotent. In French, a patient who is incontinent will sometimes say: "J'ai 
fait sous moi” (lit. 'I did it under myself'). In English, the intestines may be designated by the terms inside and innards, and in French, by the term entrailles (lit. 'insides').

In English, some patients may say they have had a double event or a full house, meaning they have gonorrhea and syphilis. When referring to AIDS, patients may say they have the (complete) package ${ }^{7}$ derived from prison slang, although package alone designates 'male and female genitals'. If a patient has gonorrhea, he or she may use the syntagm a dose, which comes from a dose of the clap (from the Middle English clapper 'rabbit-hole', from the Old French clapoire, originally 'rabbit burrow' but given a slang extension to 'brothel').

When referring to her menstrual period, an English patient may use the verb see: "I saw five days" ("my menstrual period lasted five days"). In French, a patient may say Je suis indisposée (lit. 'I'm indisposed') when menstruating. Pascal Bouché (1994: 452) mentions the French expression $\mathrm{Je}$ (me) vois, which would be the equivalent of the English 'I see', as in: “Docteur, je ne vois rien depuis trois mois", meaning 'I have not menstruated for three months'. Whether in English or French, there are various euphemisms related to menstruation that are based on vagueness: e.g. Fr. mes affaires ('my business'), mes histoires ('my stories') and mes trucs ('my things'), and Eng. thingies, the thing, the other or women's troubles. Because the word menses itself comes from the Proto-Indo-European *me(n)ses ('month, moon'), we can observe that many are related to the ideas of periodicity and moon: e.g. Eng. that time of the month, monthlies, days of the month, lady days, calendar days, moon time, and Fr. mes mois ('my months') and mes lunes ('my moons'). Also a taboo, menopause is usually called change of life, or simply the change in English, and retour d'âge (lit. 'return of age') in French.

As it is still taboo, euthanasia is often also referred to using euphemisms based on phrasal verbs: e.g. Eng. put down and put to sleep. Death in general is, in our Western culture, a major source of embarrassment and therefore of euphemisms that resort to the notion of vagueness: e.g. Eng. pass away, go out, take off, etc. and Fr. partir ('depart'), s'en aller ('go away'), quitter ('leave'), etc.

\footnotetext{
${ }^{7}$ Source: www.fr.urbandictionary.com.
} 


\subsection{Reduction: LESS OF FORM IS LESS OF CONTENT}

Shortening is a common way to talk about health-related topics that might be embarrassing. Total hysterectomy is usually referred to as la totale in French (total hys in English). Another way to euphemize is by clipping the word or using the first letter, which is illustrated, in English, by hypos for 'hypoglycemia' or miss* (see Parkinson 1999: 199) for 'miscarriage', and the big M for 'menopause' or the big $C$ for 'cancer'.

In French, patients rather speak about IVG (interruption volontaire de grossesse) when referring to abortion. In American English, patients may use $A F$ (Aunt Flo), itself derived from a metaphor (a visit from Aunt Flo* by analogy with flow), to refer to menstruation. In American English, the "visit" notion may be used to refer to taboo functions (e.g. visit Uncle Grumpy* for 'defecate'; have a visit from Uncle Ralph* for 'vomit'; have a visit from Uncle Floyd* for 'have hemorrhoids'; etc.) and conveys the idea of the patient being a victim of an unwanted phenomenon. In French, patients may use MST (maladie sexuellement transmissible) to refer to a venereal disease. English patients will use $H P V$ for 'human papilloma virus' and $D \& C$ ('dilat(at)ion and curettage') for 'abortion'.

Words that refer to certain embarrassing diseases (usually venereal, digestive or psychiatric) can be shortened. In English, mono stands for 'mononucleosis'; herp for 'herpes'; chlam or the $c(h)$ lam for 'chlamydia'; trich for 'trichomonase'; and syph for 'syphilis'. In French, patients tend to shorten "blennorragie" to blenno, "gastroentérite" to gastro, "schizophrène" to schizo, and "paranoia(c)" to parano.

Drugs such as anxiolytics and antidepressants may also be shortened and nicknamed: seckies (Seconal $\left.{ }^{\circledR}\right)$, vals (Valium $\left.\AA\right)$, nembies (Nembutal $\left.{ }^{\circledR}\right)$, mandies (Mandrax $\left.®\right)$, tuinies (Tuinal $\left.{ }^{\circledR}\right)$, and mogies (Mogadon $\left.®\right)$ in English. This strategy may well reflect how comfortable patients feel with these drugs (Faure 2014). Another example is the contraceptive pill: the pill in English and la pilule in French, in which we observe a thematizing process ${ }^{8}$ with the use of the definite article in both languages.

Some terms are reduplications of reduced syllables. For example, French patients may use caca (from the Latin cacare 'crap*'), an expression which is considered to be childish, and its

\footnotetext{
${ }^{8}$ This process indicates a distance between the concrete object (e.g. a particular pill) and the concept itself (e.g. contraception), knowledge of which is supposed to be shared by everyone (e.g. the radio, the Internet, etc.).
} 
urinary equivalent pipi, the reiteration of the first syllable of pisser* (from the Latin onomatopoeic verb pissiare 'urinate'). They may also resort to childish onomatopoeic terms such as zizi for the male and zézette for the female genitalia. In English, the same phenomenon can be observed: pee-pee from piss and pooh-pooh from poop, which according to Eric Partridge (1977: 511), comes from the Middle English word poupen or popen ('break wind'). According to Robert Chapman (1998), poop came into use with its current meaning around 1900.

\subsection{Analogy: THE HUMAN BODY IS A MACHINE/ORGANS ARE CONTAINERS}

The analysis of the corpora I used reveals that most metaphors we encounter in patientese derive from one megametaphor: THE HUMAN BODY IS A MACHINE - hence the expression my engine's not working properly to refer to cardiac problems in English. This conception originates from iatromechanics, a theory which saw the human body as a mechanism and which was widespread in the seventeenth century. If THE BODY IS A MACHINE, we can open part of it: e.g. in English, a patient will say: "I had my bowels opened", which, although it sounds worrying, simply means he has defecated, and "my lungs aren't opening", which means that he cannot breathe properly.

As THE BODY IS A MACHINE, the GUS (genito-urinary system), RS (respiratory system) AND GIS (gastro-intestinal system) ARE TUBES, a metaphor that can be illustrated by the use of lose in English and perdre in French: Eng. lose one's waters and Fr. perdre les eaux, which both designate a rupture of the amniotic sac. English patients may say: "I have lost the lot" for "vomit" or "I have lost my baby" for "miscarriage". In English, patients may say: "I cannot hold my water/motions" meaning "I am incontinent", which, in a French patient's speech, can translate into "Je ne peux pas me retenir" (lit. 'I cannot hold myself'). In case of vaginal discharge, an English patient may say: "something comes away from me". The urinary system will often be referred to, in American English, as plumbing and in British English, as waterworks. In French, tuyauterie 'pipes' may be used. In the English expression "my tubes are filled up", the word tubes means 'lungs', whereas in "I had my tubes blown", the word means 'the uterine tubes'. In English, the trachea is usually referred to as the windpipe, the vagina may be designated as the birth canal, the urethra as the pipe, and the esophagus is also called the food pipe and the gullet in English and le gosier in French, both latter words descending from the Old French golet 'the neck of a bottle'. In French, the trachea can be called le tuyau 'the pipe'. 
As OUR SYSTEMS ARE TUBES, they absorb matters/substances: Eng. take in/go down for 'swallow' and keep in; Fr. faire de la rétention (lit. 'have retention'). They eliminate matters/substances: e.g. in English, when associated with stools/motions and water, pass will mean respectively 'defecate' and 'urinate'; bring up/throw up are synonyms for "vomit"; cough up associated with blood or sputum/phlegm means 'expel by coughing'. In French, rendre (lit. 'give back') is a synonym for "vomit". In English, "it came away" usually means that the patient had a miscarriage; "I did away with it" and its French equivalent "Je l'ai fait passer" mean she got aborted; and "I had all taken away" that she has had total hysterectomy. Sometimes, our systems break matters/substances: e.g. in English, the expression break one's waters designates the rupture of the amniotic sac, and break wind means 'expel gas from the anus'. As tubes, our systems can leak (Fr. avoir des fuites urinaires [lit. 'have urinary leakage']).

If OUR SYSTEMS ARE TUBES, OUR ORGANS ARE CONTAINERS: e.g. in English, bellows for 'lungs' and belly for 'abdomen', both from Proto-Germanic *balgiz 'bag'. In French, the abdomen is also called le bide or le bidon (from a word meaning 'container'), une bedaine (a word that used to designate 'a vase') and le buffet 'sideboard'; bag and sack for 'scrotum' (in French, the scrotum can be called le paquet 'the packet'); air sacs for 'alveoli'; the voice box designates 'the larynx' and the brain box 'the head'. In French, the head can be called le caisson (lit. 'box' or 'case'). The word box can also refer to the uterus or the vagina. The thorax might be designated under the term the chest (from the Indo-European *kista 'woven container') and the barrel in English, and le coffre, la caisse 'the box' or le baquet 'the tub' in French.

Our organs may contain all sorts of objects: e.g. in English, the expression pins and needles refers to "paresthesia". They may also contain substances such as vapour: e.g. a French patient may say: "J'ai des vapeurs", meaning they suffer from hot flushes, or "Je suis tombé dans les vapes", a synonym for "faint". Our organs may even contain animals such as cats, frogs, butterflies or ants: e.g. in French, the idiom avoir un chat dans la gorge (lit. 'have a cat in one's throat') refers to hoarseness and corresponds to the English have a frog in one's throat, and avoir des grenouilles dans le ventre (lit. 'have frogs in one's belly') designates 'rumbling in the stomach'. In English, have butterflies in one's stomach is a synonym for stress, and in French, avoir des fourmis dans les jambes (lit. 'have ants in one's legs') is a way of referring to paresthesia. 
Some ORGANS ARE TOOLS/PIECES OF EQUIPMENT (e.g. Eng. belly button for 'navel' and rod, stick and equipment for 'penis'; Fr. pinces 'pincers' for "legs" or "fingers"). Some organs can run (e.g. Eng. running/runny noseleyes), pulsate (e.g. Eng. the ticker and Fr. le palpitant/battant for 'the heart') and turn (e.g. in French, avoir la tête qui tourne [lit. 'have one's head spinning'] and tourner de l'œeil [oeil 'eye'], which mean respectively 'feel dizzy' and 'faint'). Some can discharge (e.g. discharge from one's vagina/eye(s)/ear(s)/nose/rectum in English, and épanchement de synovie [lit. 'synovial effusion'] in French). ${ }^{9}$ Some can be blocked (blocked noselears in English and nez bouché in French) by stones 'calculi' or clots 'emboli', or descend (descente d'organe [lit. 'organ descent'] in French is a synonym for 'organ prolapse').

\section{Pedagogical implications and recommendations}

Although LMP teachers tend to focus on teaching technical language, it may be assumed that non-native English or French healthcare professionals do not generally encounter difficulty in understanding and using technical terms, which in many cases are translingual. The main difficulty stems from a lack of knowledge of the lay terms and idioms used by patients. Therefore, it seems essential to integrate this parameter in LMP classes, especially when the objective of the course is to help healthcare professionals practice medicine in a foreign environment.

To do so, I first suggest raising non-native English- or French-speaking healthcare professionals' awareness of the duality of medical discourse by opposing technical to lay terms. Although this phenomenon might vary from one language to another in its extent, it is to be found in most languages. Yet some learners may not be aware of its existence in languages other than their own. Lay terms can be taught via vocabulary lists. As idioms are mostly metaphorical and therefore embedded in culture, I think that activating learners' pre-existing knowledge will help them retain the new information more easily. In a comparative approach, the LMP teacher should point out the similarity between the learners' L1 and L2 and highlight, as I did above, the metaphor(s) from which many idioms derive.

Although medical research has made much progress over the centuries, some patients (and healthcare professionals) still use terms that descend from ancient theories: e.g. the Hippocratic

\footnotetext{
9 The English equivalent is "water on the knee".
} 
humoral theory with Eng. rheumatism and Fr. rhumatisme. Therefore, studying the history of medical language is an effective way of helping learners explore both the technical and lay languages diachronically. Indeed, in medicine, paradigms have changed rapidly over time but the language itself has always been slow to adapt (Hamburger 1982).

It is also important to underline the fact that sometimes, healthcare professionals who are native speakers of French or English will use the lay vernacular term rather than the more technical Latin one. For example, instead of variola, English healthcare professionals prefer the "national" term smallpox, made of the word pox, which emerged in Old English as pocc "pustule, blister, ulcer', from the Germanic *puh(h)- 'swell up'. Likewise, in English, chickenpox is still preferred to varicella, whose name descends from the Latin varius 'spotted', and measles, a word which comes from the Indo-European root *sme- 'smear', is preferred to rubeola. Therefore, the LMP teacher needs to make sure the learners know the terms that are in actual use.

Despite the progressive abandonment of eponyms in technical medical language, many patients still use them: e.g. Eng. Down's, named after John Langdon Down, a British physician. The term is so institutionalised that British patients say "the Down". In French also, various syndromes are commonly referred to by their eponyms such as la maladie d'Addison (Eng. Addison('s) disease), which owes its name to Thomas Addison, a British physician, rather than by their orthonyms: e.g. insuffisance surrénalienne chronique (Eng. 'chronic adrenal insufficiency'). When referring to body parts, English and French patients will still favour eponyms: e.g. Eng. Fallopian tubes and Fr. trompes de Fallope (named after Gabriele Falloppio, an Italian anatomist) are preferred respectively to uterine tubes and trompes utérines. Therefore, learners should be taught the most commonly used eponyms as well as their various translations: e.g. Charcot's disease in British English and Lou Gehrig's disease in American English for 'amyotrophic lateral sclerosis'.

Lay medical language is sometimes based on a lack of knowledge and understanding of human anatomy and physiology (Dirckx 1983: 132). For instance, when English-speaking patients complain about heartburn, they are referring not to heart problems but to gastric acid reflux. Likewise, French-speaking patients may say they have mal au cour (lit. 'heart pain') when they express nausea. In French, patients will talk about une crise de foie (literally 'a liver crisis') as a way to complain about indigestion, and backache may be referred to as un tour de 
rein ('a twist of the kidney'). Learners' attention should be drawn to the most common misconceptions and their consequences on patients' (mis)use of the medical terminology.

All the suggestions above imply that LMP teachers need to be knowledgeable in technical and lay medical terminology as well as in the relation between linguistic usage and medical culture. As mentioned before, a comparative approach between L-C1 ${ }^{10}$ and L-C2 helps learners understand and remember the terms and their historical, cultural, psychological, political and scientific motivation.

\section{Conclusion and perspectives}

Over the last ten years, there has been a huge increase in the number of foreign doctors practising medicine as non-native speakers of their patients' language. Although they may be familiar with the technical medical terminology - mostly made up of Latin and Greek roots and thus usually translingual - they can encounter difficulties understanding the words and phrases that English and French patients may use to refer to health-related issues, thus leading to misunderstandings that have sometimes resulted in death. ${ }^{11}$

Indeed, the language patients use when referring to their organs, bodily functions and symptoms teems with various figures of speech among which the most common is euphemism since it is, in lay medical terminology, a common way to avoid talking too crudely about what is taboo or to make the concept behind the name less frightening.

In the corpora I used, which comprised textbooks and lexicons dealing with English and French for medical purposes, I uncovered three main processes from which most euphemisms used by English and French-speaking patients are created: widening (VAGUER IS BETTER), reduction (LESS OF FORM IS LESS OF CONTENT) and analogy (THE BODY IS A MACHINE and ORGANS ARE CONTAINERS). Although English, a Germanic language, and French, a Latin language, do not share the same origin, the analysis of the corpora revealed that patients resort to the same processes in both languages because their bodily experience and their medical culture are similar.

After presenting a typology of the most common euphemisms used by native English or French speaking patients, I made suggestions as to what should be taught and how it should be taught in an LMP course designed for foreign healthcare professionals.

\footnotetext{
${ }^{10}$ Language-Culture.

${ }^{11}$ See the Bernard Delvigne case in 2006 for the UK.
} 
Studies of patients' understanding of medical words and concepts have proved very useful from a medical point of view as their results have undoubtedly contributed to the improvement of doctor-patient communication, but they could also provide evidence of what Gwyn (2002: 7) observed: "Medical terms are scattered throughout our conversations, and a much wider knowledge of terminology is discernible in everyday discourse than existed a generation ago." Indeed, due to the popularity of medical TV series such as House M.D. or Grey's anatomy and the availability of online health information, one can assume that patients' terminology has gained in technicality and therefore that patients may be starting to use technical terms as new euphemisms. Yet, to investigate usage frequency and the progressive pre-eminence of technical terms over lay terms during medical interviews, more research should be based on statistical analyses of larger and more authentic corpora such as the British National Corpus as well as on questionnaire surveys addressed to healthcare professionals and their patients. This research could adopt a systematic and dynamic approach to identify lay expressions, map them to corresponding technical terms and concepts, and test their familiarity for the intended lay audience. In turn, this research could lead to the assessment of the degree of foreign healthcare professionals' familiarity with lay terms and provide a methodology to improve their understanding of "common" health expressions, concepts and explanatory models shared within cultural, geographical and familial discourse groups.

\section{References}

Allan, Keith \& Kate Burridge. 2006. Forbidden words, taboo and the censoring of language. New York: Cambridge University Press.

Chapman, Robert. 1998. The dictionary of American slang. New York: Collins.

Dirckx, John. 1983 [1976]. The language of medicine, its evolution, structure and dynamics. New York: Praeger.

Faure, Pascaline. 2012. L'anglais médical et le français médical: analyse linguistico-culturelle. Paris: EAC.

Faure, Pascaline. 2014. Du sildenafil citrate au Viagra ou l'art délicat de nommer les médicaments. Terminology 20(1). 75-91.

Faure, Pascaline. 2015. La langue du patient, de l'archaïsme à l'orthonyme : analyse comparative français/anglais. Les Cahiers de Lexicologie 106(1). 213-228. 
Gwyn, Richard. 2002. Communicating health and illness. London: SAGE.

Hamburger, Jean. 1982. Introduction au langage de la médecine. Paris: Flammarion.

Keyes, Ralph. 2010. Unmentionables. London: John Murray.

Lakoff, George \& Mark Johnson. 2003 [1980]. Metaphors we live by. Chicago: University of Chicago Press.

Marsh, Joseph. 1998. Word crimes: Blasphemy, culture, and literature in nineteenth-century England. Chicago: University of Chicago Press.

Ogden, Jane \& Ruben Branson. 2003. What's in a name? An experimental study of patients views of the impact and function of a diagnosis. Family Practice 20(3). 248-53.

Ong, Lucille, Hanneke de Haes, Aloysia Hoos \& Frits Lammes. 1995. Doctor-patient communication: A review of the literature. Social Science and Medicine 40(7): 903-918.

Partridge, Eric. 1977. Origins: A short etymological dictionary of modern English. Abingdon, UK: Routledge.

Pinker, Steven. 2007. The language instinct. New York: Harper.

Shuy, Roger W. 1983. Three types of interference to an effective exchange of information in the medical interview. In Sue Fisher \& Alexandra Todd (eds.), The social organization of doctor-patient communication, 189-202. Washington, DC: Center for Applied Linguistics.

Tailor, Anisha \& Jane Ogden. 2009. Avoiding the term "obesity": An experimental study of the impact of doctors' language on patients' beliefs. Patient Education and Counselling 76(2). $260-274$.

Tanguy, Ludovic, Cécile Fabre, Lydia-Mai Ho-Dac \& Josette Rebeyrolle. 2011. Caractérisation des échanges entre patients et médecins: approche outillée d'un corpus de consultations médicales. Corpus [Online]. http://corpus.revues.org/2058 (accessed 8 May 2014).

Tournier, Jean. 2004. Précis de lexicologie anglaise. Paris: Ellipses.

Williams, Nigel \& Jane Ogden. 2004. The impact of matching the patient's vocabulary: A randomized control trial. Family Practice 21(6). 630-635.

Williams, Joseph. 1975. Origins of the English language: A social and linguistic history. New York: Free Press.

Young, Meredith, Geoffrey Norman \& Karin Humphreys. 2008. The role of medical language in changing public perceptions of illness. PLOS ONE 3(12), e3875. http://www.plosone.org (accessed 15 May 2014). 
Zeng-Treitler, Qing, Sergey Goryachev, Tony Tse, Alla Keselman \& Aziz Boxwala. 2008.

Estimating consumer familiarity with health terminology: A context-based approach.

Journal of the American Medical Informatics Association 15(3). 349-356.

Zeng-Treitler, Qing \& Tony Tse. 2006. Exploring and developing consumer health vocabularies.

Journal of the American Medical Informatics Association 13(1). 24-29.

\section{References for the corpora}

Bouché, Pascal. 1994. Les mots de la médecine. Paris: Belin.

Fassier, Thomas \& Solange Talavera-Goy. 2008. Le français des médecins. Grenoble: Presses Universitaires de Grenoble.

Glendinning, Eric \& Beverly Holmström. 2004. English in medicine. Cambridge: Cambridge University Press.

Glendinning, Eric \& Ron Howard. 2007. Professional English in use: Medicine. Cambridge:

Cambridge University Press.

McCullagh, Marie \& Ros Wright. 2008. Good Practice. Cambridge: Cambridge University Press. Mourlhon-Dallies, Florence. 2004. Santé-médecine.com. CLE International.

Parkinson, Joy. 1999 [1969]. Manual of English for the Overseas Doctor. Elsevier/Churchill Livingstone.

Quérin, Serge. 2007. Dictionnaire des difficultés du français médical. Canada: Maloine.

Sales, David. 2004. Medical IELTS: A Workbook for International Doctors and Plab Candidates. Radcliffe Publishing.

\section{Appendix}

\begin{tabular}{llll}
\hline Type of metaphors & Signified & English & French \\
\hline VAGUER IS BETTER & the female genitals & down below/down there & en bas \\
the male genitals & the parts & les parties \\
& the grivates & l'entrejambe \\
& the crotch & \\
& the loins & the front passage & devant \\
the vagina & up inside & \\
& the back passage &
\end{tabular}




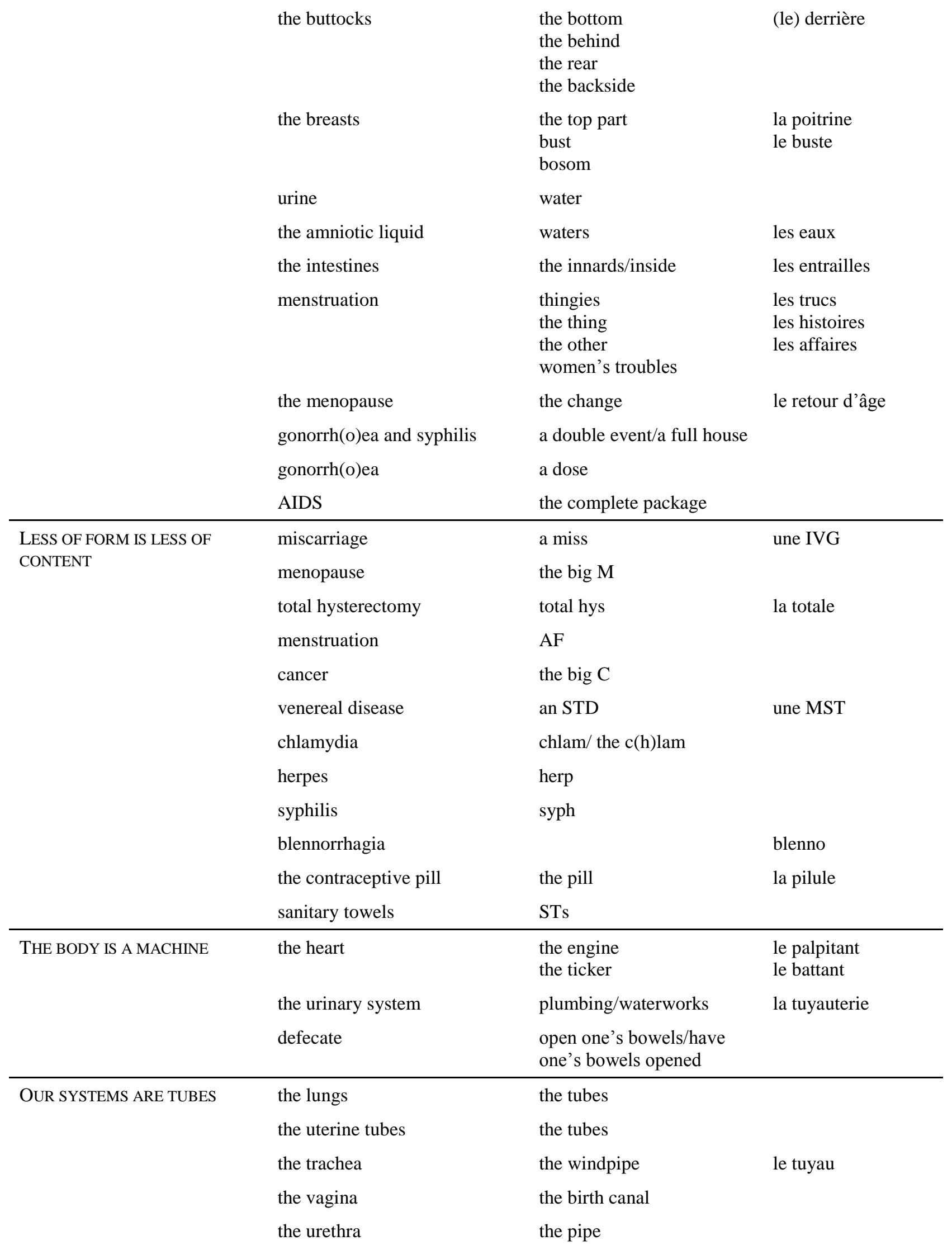




\begin{tabular}{|c|c|c|c|}
\hline & \multirow{3}{*}{$\begin{array}{l}\text { the (o)esophagus } \\
\text { incontinence } \\
\text { rhinitis }\end{array}$} & the food pipe & \multirow{3}{*}{$\begin{array}{l}\text { le gosier } \\
\text { des fuites urinaires } \\
\text { le nez qui coule }\end{array}$} \\
\hline & & urinary leakage & \\
\hline & & a runny/running nose & \\
\hline \multirow[t]{7}{*}{ ORGANS ARE CONTAINERS } & the larynx & the voice box & \\
\hline & the lungs & the bellows & \\
\hline & the abdomen & the belly & $\begin{array}{l}\text { le bidon } \\
\text { la bedaine } \\
\text { le buffet }\end{array}$ \\
\hline & the scrotum & $\begin{array}{l}\text { the bag } \\
\text { the sac } \\
\text { the package }\end{array}$ & le paquet \\
\hline & the alveolus & the air sac & \\
\hline & the head & the brain box & le caisson \\
\hline & the thorax & $\begin{array}{l}\text { the chest } \\
\text { the barrel }\end{array}$ & $\begin{array}{l}\text { le coffre } \\
\text { la caisse } \\
\text { le baquet }\end{array}$ \\
\hline
\end{tabular}

\section{Bionote}

\section{Pascaline Faure}

Pascaline Faure has a PhD in medical English, for which she completed three years in medicine. She is an assistant professor in English for medicine and has been Director of the Medical English Department of Pierre and Marie Curie School of Medicine for 14 years. Her major works examine the nature of medical language (etymology, neologism, abbreviations and discourse) and the impact of English on other European medical languages. 